\title{
Persistence of Grazing Tolerant Lucernes under Australian Conditions
}

\author{
J.C. SEWELL ${ }^{1}$, R.D. HILL ${ }^{1}$, and J.REICH ${ }^{2}$ \\ ${ }^{1} P G G$ Wrightson Seeds, Ballarat Research Farm, Australia \\ ${ }^{2}$ Cal/West Seeds, California, USA \\ jsewell@pggwsa.com.au
}

\begin{abstract}
Recent experiments have demonstrated that lucerne (Medicago sativa) varieties selected for grazing tolerance will persist far better when grazed for extended periods than varieties not selected for grazing tolerance. A field experiment, with lucerne varieties representing a range of winter activity ratings, was conducted at Ballarat. After 2.5 years of rotational grazing the experiment was continuously grazed for 173 days from late spring to early autumn at a stocking rate equivalent to 50 sheep/ha. This intensity is not considered much higher than some farmers would adopt during a drought. Ground cover of some varieties had significantly declined by the end of the grazing period but further decline occurred throughout the following winter months while livestock were excluded. The grazing tolerant lines persisted better than most standards, even those within the same dormancy category, with some standards almost completely dead while the grazing tolerant lines were over $60 \%$ alive.
\end{abstract}

Keywords: grazing tolerance, lucerne (Medicago sativa), persistence

\section{Introduction}

Lucerne (Medicago sativa) is the most widely grown perennial pasture legume in Australia (Lodge 1991). It will persist if strict management practices are adhered to and it is well understood that, for longterm productivity, lucerne pastures require rotational grazing (Leach 1968). Numerous studies recommend a minimum spell period of around 35 days and a short grazing period (Lodge 1991). These practices should provide a reasonable balance between persistence, quality, yield and animal safety. Nevertheless, many Australian farmers find ideal grazing management techniques impracticable and hard to sustain under tough seasonal conditions.

There are a number of factors which contribute to the low rate of adoption of ideal grazing rotations. Paddocks are often too large and high costs are associated with sub-dividing and watering in broadacre pasture systems, additional management is required and perhaps there is a poor understanding of the benefits of rotational grazing. However, the greatest obstacle to adoption is that over a long dry summer, when the only green feed on the farm is lucerne, farmers will leave their valuable stock on lucerne for extended periods despite the, known, consequences.

The adverse effects of continuous grazing on lucerne plants have been reported by Smith et al. (1989) and set-stocking with high stocking rates under dry Australian conditions will most likely result in a rapid decline in stand persistence (Brownlee 1973). There is a strong correlation between winter dormancy and grazing tolerance (Humphries et al. 2006; Bouton \& Gates 2003), but there are also a number of other traits that contribute to differences in lucerne persistence under grazing. Smith et al. (1989) and Humphries et al. (2006) cite various authors who have found that grazing tolerance in lucerne has been linked to deep set crowns, decumbency or prostrate habit, subsurface budding, broad crowns, prolific and non-synchronous budding, extended periods of budding, maintenance of leaf area under grazing and maintenance of root carbohydrates.

A 6-year grazing tolerance screening programme, which was conducted in the United States by Cal/West Seeds, combined elite breeding lines and successful commercial cultivars. Experiments were continuously grazed by both sheep and beef cattle for lengthy periods at high stocking rates, following the protocol developed at the University of Georgia and the North American Alfalfa Improvement Conference (NAAIC) standard test protocol (Bouton \& Smith 1998). Further screening of 24 lines of elite material from this programme, and 14 commercially available cultivars, was conducted at two sites in Australia by Wrightson Seeds from 1999 to 2005 (Salmon \& Hill 2008). After 4 years of rotational grazing, the Ballarat (south western Victoria) experiment was subjected to continuous grazing for 2 years (40 sheep/ha with a 2-month spell after 10 months). A similar experiment was conducted at Gundagai (southern New South Wales) where a severe drought was experienced; final selections were made from plants subjected to this extreme stress. Almost all of the US lines developed for grazing tolerance persisted better than the 'Australian' commercial cultivars. Two test lines were identified as having an ideal balance of persistence, winter activity and yield 
Table 1 Ground cover percentages per metre row for the pre-grazing, first assessment $\left(7^{\text {th }}\right.$ April 2010) and final assessment $\left(8^{\text {th }}\right.$ September 2010) and cumulative yield (DM t/ha) before continuous grazing.

\begin{tabular}{|c|c|c|c|c|c|c|c|c|}
\hline \multirow[t]{2}{*}{ Cultivar } & \multirow{2}{*}{$\begin{array}{l}\text { Winter } \\
\text { Activity }\end{array}$} & \multirow{2}{*}{\multicolumn{2}{|c|}{$\begin{array}{c}\text { Cumulative DM t/ha } \\
\text { until 2/02/2009 }\end{array}$}} & \multicolumn{5}{|c|}{ Ground Cover \% } \\
\hline & & & & \multirow[t]{2}{*}{$\begin{array}{c}\text { Initial } \\
18 / 12 / 2006\end{array}$} & \multicolumn{2}{|c|}{$\begin{array}{c}\text { First }^{\dagger} \\
7 / 4 / 2010\end{array}$} & \multicolumn{2}{|c|}{$\begin{array}{c}\text { Final }^{\dagger} \\
8 / 9 / 2010\end{array}$} \\
\hline \multicolumn{8}{|c|}{ Non-grazing tolerant varieties } & \\
\hline Aurora & 6 & 19.52 & defg & 94 & 51 & gh & 23 & fghij \\
\hline Australis & 9 & 21.85 & $a b c$ & 97 & 29 & $\mathrm{i}$ & 5 & $\mathrm{k}$ \\
\hline Genesis & 7 & 18.36 & $g$ & 92 & 66 & ef & 28 & fghi \\
\hline Hunterfield & 6 & 18.68 & $\mathrm{fg}$ & 95 & 70 & e & 47 & de \\
\hline Icon & 6 & 21.40 & abcd & 93 & 38 & hi & 14 & $\mathrm{ijk}$ \\
\hline Kaituna & 5 & 22.33 & a & 92 & 76 & cde & 36 & ef \\
\hline PGWS-4 & 6 & 20.42 & abcdefg & 94 & 47 & gh & 18 & hijk \\
\hline PGWS-6 & 7 & 22.25 & $a b$ & 94 & 78 & bcde & 35 & efg \\
\hline PGWS-7 & 7 & 20.04 & bcdefg & 94 & 55 & $\mathrm{fg}$ & 25 & fghi \\
\hline Sardi 7 & 7 & 19.07 & efg & 93 & 43 & ghi & 20 & ghij \\
\hline SD 54Q53 & 4 & 20.61 & abcdef & 92 & 69 & ef & 35 & efg \\
\hline SD L56 & 5 & 21.54 & abcd & 93 & 72 & de & 32 & efgh \\
\hline UQL-1 & 7 & 21.21 & abcde & 95 & 38 & hi & 10 & $\mathrm{jk}$ \\
\hline Mean & & 20.56 & & 94 & 56 & & 25 & \\
\hline \multicolumn{9}{|c|}{ Grazing tolerant varieties } \\
\hline PGWS-1 & 5 & 20.96 & abcde & 93 & 87 & $a b c$ & 67 & c \\
\hline PGWS-2 & 4 & 20.75 & abcdef & 89 & 89 & $a b c$ & 71 & $\mathrm{bc}$ \\
\hline PGWS-3 & 6 & 20.25 & abcdefg & 96 & 77 & cde & 68 & $\mathrm{bc}$ \\
\hline PGWS-5 & 3 & 19.75 & cedefg & 94 & 93 & a & 82 & $a b$ \\
\hline Stamina 5 & 5 & 19.95 & cdefg & 96 & 92 & $a b$ & 90 & a \\
\hline Stamina GT6 & 6 & 20.83 & abcdef & 97 & 85 & abcd & 61 & $\mathrm{~cd}$ \\
\hline Venus & 5 & 20.55 & abcdefg & 89 & 91 & $a b$ & 76 & $a b c$ \\
\hline Mean & & 20.43 & & 93 & 88 & & 74 & \\
\hline LSD (0.05) & & 2.25 & & 4.5 & 14.4 & & 15.5 & \\
\hline CV\% & & 7.8 & & 3.4 & 15.1 & & 25.9 & \\
\hline
\end{tabular}

${ }^{\dagger}$ Means with the same letters within a column are not significantly different $(P<0.05)$

and released as 'Stamina 5' and 'Stamina GT6'.

Here we report a subsequent experiment established in 2006 at the PGGWrightson Seeds Ballarat Research Farm to evaluate new experimental grazing-tolerant lines, including selections taken from the 1999-sown experiments (above) and commercial cultivars.

\section{Methods}

Experimental treatments and design

The NAAIC standard test protocol to screen lucerne for grazing tolerance (Bouton \& Smith 1998) was used, however there was one major exception being that sheep were used in this experiment, rather than cattle, for closer grazing. 
Figure 2 Relationship between winter activity rating and overall decline in stand density (GC\%). R2 = 0.499 .

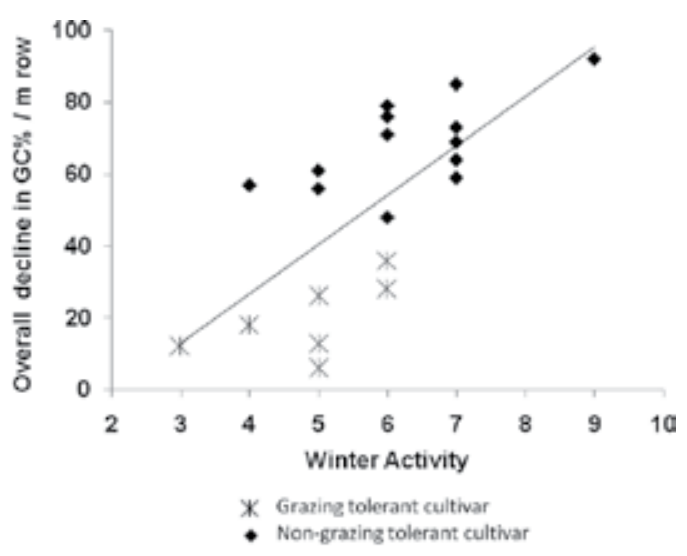

The trial was drill-sown on the $1^{\text {st }}$ of September 2006 at the PGGWrightson Seeds Research Farm at Ballarat (375'스. $143^{\circ} 95^{\prime}$ E), south-western Victoria. The soil is a deep red Krasnozem derived from volcanic ash. The site was previously limed, sprayed with 3 lt/ha of Roundup 1 month prior to cultivation, and the seedbed was prepared to a fine tilth.

There were 20 entries comprising 13 commercially available cultivars representing various winter activity ratings, including 'Stamina 5' and 'Stamina GT6' as the grazing tolerant control types, and seven experimental lines of varying winter-activity ratings labelled PGWS1 to PGWS-7. PGWS-1,2,3 and 5 were specifically developed for grazing tolerance. The seeding rate was $20 \mathrm{~kg} / \mathrm{ha}$ and all seed was lime coated and inoculated, and sown with a 10-row, precision cone-seeder and roller.

Plots of $1.30 \times 5.08 \mathrm{~m}$ were laid out as a randomly allocated factorial design with four replicates. The plot area was surrounded by a $10-\mathrm{m}$ border sown to lucerne. Drinking water, a supplement feeding area and a shade house were situated along the fence-lines and $10 \mathrm{~m}$ away from the trial plots.

\section{Grazing}

After reaching an initial flowering stage, the experiment was rotationally grazed/cut for 2.5 years and yields were recorded. After the $3^{\text {rd }}$ October 2009 the trial was continuously grazed with 14 crossbred wethers (equivalent to 50 sheep/ha) until the $25^{\text {th }}$ March 2010 (173 days). The sheep were fed a supplement of grain towards the end of the grazing period. After an assessment of ground cover was made, the lucerne was chemically 'winter cleaned' (2.5 lt/ha diuron; 2 lt/ha diquat) and plants allowed to recover to ensure no depletion of the stand occurred due to chemical application. The experimental plots were then spelled until September when, after 3 days of grazing, a further assessment was made.

\section{Measurements and Analysis}

Ground cover was measured on the $18^{\text {th }}$ December 2006. Subsequent measurements were made 13 and 7 days, respectively, after de-stocking in April and September 2010. These intervals allowed the lucerne to regrow to $5-7.5 \mathrm{~cm}$ height. The proportion of a $1.0 \mathrm{~m}$ length of drill row supporting lucerne growth was visually assessed from six randomly selected sites within each plot to provide an estimate of ground cover. Analysis of variance was carried out using the 'Statistix 2.0’ program.

\section{Results and Discussion}

Differences in persistence between the grazing tolerant and the non-grazing types had become visually apparent during the first grazing period and were reflected in the April 2010 assessment (Table 1). Stand density was significantly reduced in the non-grazing tolerant types after this initial 5 months of set-stocking. Despite minimal grazing over the winter the non-grazing tolerant types continued to decline, presumably due to their depleted energy reserves, and the September assessment revealed significantly less ground cover than the April assessment.

Defoliation in autumn can reduce the level of root carbohydrate reserves in the plant, the level of winter hardiness and survival and the number of crown buds available for spring growth (Smith 1972). Winter injury from extreme cold is unlikely to occur in Australia, although autumn and winter grazing may affect longterm persistence (Lodge 1991), particularly for nongrazing tolerant types. Brummer \& Bouton (1992) suggested that the ability of cultivars to produce and store high levels of total non-structural carbohydrates may enhance grazing tolerance. This physiological attribute is particularly important through the critical autumn period under continuous grazing.

Stamina 5 was the most persistent cultivar with a $6 \%$ decline in stand density over 4 years. Some of the experimental lines selected under continuous grazing persisted well (e.g., PGWS-5, 3 and 2) but none were superior to Stamina 5. Almost all of the lines developed for grazing tolerance persisted significantly better than the non-grazing tolerant types, irrespective of dormancy group. The only exception to this was Hunterfield (47\% final ground cover). All the grazing tolerant lucernes had final ground covers greater than $60 \%$.

These results show that selection of diverse winter activity groups for grazing tolerance can be effective in lucerne. Considerable differences in persistence occurred between varieties within the same winter activity group - Stamina GT6 (61\%) versus Icon (14\%) 
both winter active 6, and Stamina $5(90 \%)$ versus SDL56 (32\%) both winter active 5. The negative correlation between higher winter activity and grazing tolerance (Fig. 1) supports previous findings (Brummer \& Bouton 1991; Smith et al. 1989). Similar results under grazing by sheep in Australia have also been recorded by Humphries et al. (2006) who reported final plant frequencies ranging from $0-13 \%$ for highly winter-active entries and $11-40 \%$ for winter dormant entries.

Improved persistence also results in reduced weed invasion (Bouton et al. 2001) and grazing tolerant lines have been shown to yield as well, or better, than nongrazing tolerant lines even under rotational stocking and mechanical hay harvesting (Bouton \& Gates 2003). Cumulative dry matter yield for the 2.5 years before the continuous grazing treatment (Table 1) indicates that there was very little difference in overall yield for the grazing tolerant and non-grazing tolerant varieties. However, the grazing tolerant varieties are likely to produce superior yields after the grazing stress due to higher plant density (Bouton et al. 2001).

Most Australian farmers understand the need for appropriate spells to enable lucerne to replenish carbohydrate reserves. In times of drought, however, lucerne will be overgrazed and the benefits of grazing tolerant lucernes such as Stamina 5 and Stamina GT6 should be significant.

\section{ACKNOWLEDGMENTS}

We wish to thank the various field staff and farm managers at the PGGWrightson Research Farm from 2006 to the present.

\section{REFERENCES}

Bouton, J.H.; Gates R.N. 2003. Grazing-tolerant alfalfa cultivars perform well under rotational stocking and hay management. Agronomy Journal 95: 1461-1464.

Bouton, J.H.; Smith S.R. Jr. 1998. Standard test to characterize alfalafa cultivar tolerance to intensive grazing with continuous stocking. pp. A-8. In: Standard tests to characterize alfalfa cultivars. $3^{\text {rd }}$ ed. Eds. Fox, C.C.; Berberet, R.; Gray, F.A.; Grau C.R.; Jessen D.L.; Peterson, M.A. North American Alfalfa Improvement Conference, Beltsville, MD.

Bouton, J.H.; Gates, R.N.; Hill, G.M. 2001. Combining the grazing tolerant trait with forage production in non-dormant alfalfa. pp. $177-182$. In: 14. Réunion Eucarpia du Groupe Medicago spp. Options Méditeraréenaes. Série A: Séminaries Méditerranéens.
Brownlee, H. 1973. Effects of four grazing management systems on the production and persistence of dryland lucerne in central western New South Wales. Australian Journal of Experiemental Agriculture and Animal Husbandry 13: 259-262.

Brummer, E.C.; Bouton, J.H. 1991. Plant triats associated with grazing tolerant alfalfa. Agronomy Journal 84: 996-1000.

Brummer, E.C.; Bouton, J.H. 1992. Physiological Traits Associated with Grazing-Tolerant Alfalfa. Agronomy Journal 84: 138-143.

Humphries, A.W.; Kobelt, E.T.; Bellotti, W.D. Auricht G.C. 2006. Tolerance of Australian lucerne germplasm to grazing by sheep. Australian Journal of Experimental Agriculture 46: 1263-1270.

Leach, G.J. 1968. The growth of the lucerne plant after cutting: the effects of cutting at different stages of maturity and at different intensities. Australian Journal of Agricultural Research 19: 517-530.

Lodge, G.M. 1991. Management practices and other factors contributing to the decline in persistence of grazed lucerne in temperate Australia: a review. Australian Journal of Experimental Agriculture 31: 713-724.

Salmon, R.W. Hill, R. 2008. Grazing tolerant lucernes - a breakthrough in lucerne persistence. pp.142-145. In: Proceedings of the $49^{\text {th }}$ Annual Conference of the Grassland Society of Southern Australia. Bairnsdale, VIC.

Smith, D. 1972. Cutting schedules and maintaining pure stands. In: Alfalfa Science and technology. American Society of Agronomy, Madison, WI. pp481-496.

Smith, S.R. Jr.; Bouton, J.H.; Hoveland, C.S. 1989. Alfalfa persistence and regrowth potential under continuous grazing. Agronomy Journal 81: 960-965.

Smith, S.R. Jr.; Bouton, J.H.; Singh, A.; McCaughey, W.P. 2000. Development and evaluation of grazing tolerant-tolerant alfalfa cultivars: A review. Canadian Journal of Plant Science 80: 503-512. 